\title{
E-portfolio as a tool of pedagogical management in the virtual information and educational environment of the university
}

\author{
Marina Likhushina*, and Galina Radchenko \\ Don State Technical University, 344003, Rostov-on-Don, Russia
}

\begin{abstract}
One of the main tasks of the modern education system is not just to transfer to students as much knowledge as possible, but rather the ability to extract it, the ability to navigate the flow of up-to-date information. The quality and reliability of the future specialist's knowledge, his ability to solve complex issues independently, and the success of his future professional activities depend on the organization of pedagogical management in the educational activities of students. The virtual educational environment is understood as an arbitrarily constructed structure of the information environment, consisting of a set of autonomous subjects which connections are nonlinear and probabilistic. The virtual educational environment implements students' life strategies and values in digital social interaction. The purpose of the research is to determine the features of using the pedagogical technology of creating a portfolio in the electronic form as a tool of pedagogical management in the virtual information and educational environment of the University. The objectives of the research are to analyze the components of the electronic portfolio of students and compare them with the stages of implementation of the pedagogical technology for creating a students' portfolio. The solution of the research tasks is based on the criterion of improving the professional literacy of the university students and evaluating their achievements using e-portfolio technology.
\end{abstract}

\section{Introduction}

Management methods are means of implementation of management actions for staff to achieve the objectives of production management. There are administrative, economic, sociological and psychological methods that differ in ways of influencing people. Methods of pedagogical management are ways of implementing managerial influences on teachers and students to achieve the goals of managing the educational process. The use of the theory of pedagogical management allows changing the entire paradigm of management in the field of education. At the same time, there is a transition from the traditional management system, characterized by dominant vertical relationships and, accordingly subject-object relations, to the system of organizational and managerial cooperation, characterized by dominant horizontal relationships and subject-subject relations. This transition is very relevant for the information educational environment, which is characterized, in particular, by developed and flexible horizontal links $[1,2,3,4,5]$. It can be stated that there is currently no single generally accepted definition of the concept of pedagogical management. Analyzing different

* Corresponding author: likhushina.marina.v@gmail.com 
views on the content of this concept, we can distinguish, relatively speaking, "narrow" and "broad" approaches to its definition. Within the framework of the conditional "narrow" approach, this concept is reduced directly to educational activities. Within the framework of the conditional "broad" approach, this concept is revealed through the management of the functioning and development of pedagogical systems. The adaptability of educational programs to the personal characteristics of students, the use of interactive elements, computer graphics, visualization of educational information, and the use of multimedia technology give way to the formation of a qualitatively new level of cognitive independence. Competent integration of modern information technologies, such as electronic software systems, in the educational process at the University contributes to the economic efficiency of educational programs by redistributing classroom hours spent in traditional forms (lectures, practical and laboratory classes) to other forms of classes, such as contact independent work and just independent work. At the same time, the main goal of the changes is to increase the mobility of students and teachers, increase their involvement and interest without significantly reducing the quality of education in general. The definition of virtual educational environment is a constantly evolving multi-level system. This system usually covers: 1) modern and traditional technologies designed to meet the need for communication between participants in educational activities in an open model of non-simultaneous individual training; 2) information resources implemented using information technologies, which may include databases and knowledge, electronic learning materials, libraries, etc.; 3) upgraded software tools, which directly include software shells, electronic communication tools.

The concept of information educational environment as one of the forms of the education system has already been considered in detail at the conceptual and technological levels in Pedagogy. We noted in our research that the information educational environment can be considered as a combination of a number of components:

- information resources containing data, information and knowledge recorded on the appropriate media;

- organizational structures that ensure the functioning and development of a single information and educational environment, in particular, the collection, processing, storage, distribution, search and transfer of information;

- means of information interaction between citizens and organizations that provide them with access to information and educational resources based on appropriate information technologies-software and hardware and organizational and normative documents.

Accordingly, next we need to consider the functions of pedagogical management in relation to the conditions of the information educational environment. Modern views consider the structure of pedagogical management includes a triad of levels. At the first level, the tasks of managing the activities of the teaching staff are concentrated. At the second level, the teacher's activity is managed. The third level of pedagogical management is focused on managing the student's activities. All three levels can be represented within the information educational environment's functioning. Among the main tasks of pedagogical management, it is necessary to include the following: goal setting and planning of the pedagogical process, resource support of the pedagogical process, ensuring high motivation of the subjects of the process, control and coordination of the pedagogical process, analysis of results. Therefore, there are the following functions of pedagogical management as a means of managing educational information system: information-analytical, motivational-target; planning and forecasting; organizational performance; monitoring; regulatory-correction. We believe that in the conditions of the information educational space, the information-analytical, planningprognostic, control diagnostic and regulatory-correctional functions will have the greatest value. Based on the analysis of the specifics of the four functions, it was determined in our research that within the information educational environment there are all the prerequisites for their continuous implementation, which gives them and all pedagogical monitoring in 
these conditions a new property - continuity. We believe that the key technology of pedagogical management within the information educational space should be the technology of ensuring continuity.

\section{Materials and Methods}

The purpose of this research is to create a pedagogical technology for effective pedagogical management of the educational process of students in a virtual educational environment of the University, which allows students and teachers to navigate the flow of educational information, effectively and timely solve issues of assessment and evaluation of students and makes it possible to provide personal support to students when working with educational materials in a virtual environment.

The objectives of this study include: 1) identification of potential threats to the virtual educational environment for personal self-development that reduce educational and motivational potential; 2) development of new and adaptation of existing methods of pedagogical management and their further integration into pedagogical technology for their most effective use in the virtual educational environment.

Pedagogical technology "Portfolio" is a way of recording, accumulating and evaluating of individual educational results of a student during a certain period of his training. The portfolio allows you to take into account the results in a variety of activities: educational, creative, social, and communicative. Portfolio is a pre-planned and specially organized individual selection of materials and documents that demonstrates the efforts, dynamics and achievements of the student in various fields.

This is a way of recording, accumulating and evaluating the students' work and results, which indicate their efforts, progress and achievements in various fields over a certain period of time. In other words, it is a form of self-expression and self-realization fixation. The portfolio provides a shift in the focus of learning outcomes from assessment to selfassessment, from what the student does not know to what he knows and can do. A significant characteristic of the pedagogical technology of the portfolio is its integration, which includes quantitative and qualitative assessments, which implies cooperation between students and teachers during its creation, and the continuity of replenishment of results $[6,7,8]$.

Portfolio technology implements the following functions in the educational process: diagnostic (changes and growth (dynamics) of indicators for a certain period of time are recorded); goal setting (supports educational goals formulated by the standard); motivational (encourages students and teachers to interact and achieve positive results); meaningful (maximum reveals the full range of achievements and work performed); developing (ensures the continuity of the development process, and training); rating (shows the range and level of skills and abilities); training (creates conditions for the formation of the foundations of qualimetric competence); corrective (encourages development within the framework conditionally set by the standard and society).

The research methodology involves performing a content analysis of virtual informationeducational environment of the University to enhance the effectiveness of the organization in the system of pedagogical management, monitoring of satisfaction of participants of educational process and training opportunities in a virtual environment on the basis of the survey and evaluation of students' learning achievements. The first direction of our research was to solve the problem of identifying potential threats in the virtual educational environment for personal self-development that reduce educational and motivational potential. The changing environment of human activity has a strong influence on it. In the system of factors that are becoming more and more important, we can especially highlight Internet technologies. They have become an integral part of people's lives, particularly those of students. Students are an independent social group engaged in the accumulation and 
assimilation of scientific knowledge and professional skills, which has a large resource for adapting to dynamically changing social contexts. Students are a part of society that has a priority of sensitivity to innovation processes, which allows them to experiment with innovations in modern society. Let's move on to the main threats to personal selfdevelopment identified in our research in a virtual educational environment. An attempt to identify the content parameters of interaction between a modern student and the virtual educational environment, which could serve as a kind of markers of threats to the subject's personality in the virtual educational environment, led to the following results

1. Use of Internet resources for training. The unique features of the network make it possible to focus on the student's independent work within the framework of specially organized activities. With the help of Internet technologies, you can organize independent work of students and develop their skills of independent activity. This will contribute to a better comprehension of theoretical material, its application in practice, and ultimately lead to an increase in the effectiveness of higher education. On the other hand, there is a threat of misuse of information resources and students' attempts to use educational Internet resources irrationally, inexpediently, and in violation of personal and copyright boundaries, that are becoming more frequent.

2. The degree of involvement in Internet communication. Internet socialization offers unlimited opportunities for students to communicate, thanks to social networks. Young people are the most active audience of users of social networks, largely preferring virtual communication to real. Many students are attracted to virtual communication by its speed, convenience, lack of spatial restrictions, the ability to find new friends, and anonymity. It is worth noting that anonymity is one of the most attractive features of Internet communication. After all, real society does not allow the individual to fully open up in communication, shackling the framework of norms and rules. Communicating virtually, a person can open up exactly as much as his desire allows, and not the desire of others. Also, when communicating on the Internet, you can choose a certain image that can serve as a possible guide for selfdevelopment and self-understanding, since in the process of mastering a new role, students will compare "I-real" and "I-virtual". However, these advantages of Internet communication in comparison with direct communication of students in the team also leads to its devaluation, depersonalization, and reduction of responsibility for their actions.

3. Online communication creates an opportunity to expand your social circle and meet people from different social groups. An important feature of virtual communication is the very rapid expansion of the circle of communication. In a virtual society, the number of students' social contacts increases, and a person's communication capabilities expand. In reality, the range of possible acquaintances is quite limited, especially with an established lifestyle. The reasons for this may include: limited time, geographical boundaries, different social status, organization of life, etc. Due to virtual socialization, the circle of communication is expanding, but, on the other hand, some note that the depth of relationships is lost. This can be considered as a consequence of the formation of value orientations. Online interaction can contribute to the development of tolerance to the environment and flexibility in communication due to contact with unfamiliar people. But, at the same time, this type of interaction often contributes to the distortion of ideas about the personalities of communicants and their semantic and value orientations. Also, due to the invariance and multiplicity of contacts and opinions, the formation of such character traits as unappreciated views and ideas in relation to the behavior of oneself or others can occur. Thus, the valuesense dominants of perception of the world in the context of virtualization of the modern educational space acquire special significance and relevance.

The second direction of our research was to solve the problem of developing new and adapting existing methods of pedagogical management and their further integration into eportfolio technologies for their most effective use in a virtual educational environment. 
Modern educational processes cannot take place without including a wide range of information resources in training, without developing the skills of processing and presenting information. The information environment created on the basis of high-tech means is seen as an integral part of the learning environment at the University. At the level of solving the problem of content analysis of information-educational environment of a University, speaking on the subject of our study, was considered a virtual educational platform of the University and carried out comparative analysis according to various criteria with other open education platforms. In our study, we identified three types of environments: knowledgeoriented, self-directed learning activities, and mixed media. Let's briefly review their content $[9,10,11,12,13]$.

The first understanding of information educational system is related to the hardware and software model of the studied area of knowledge, which is embedded in a specific training method. In creating environments, a cognitive approach is actively used, which is based on the internal structure of human knowledge, on the system-structural properties of the studied discipline. Environments of this type can be either «open», for example, when program shells allow the teacher to replace or add new content, or «closed». External information resources (virtual libraries, e-textbooks) are included in the learning process, but are usually used in an organizational context, as a supplement to the content of the main course in a particular field of knowledge.

The second type is characterized by the belief that learning is an organic derivative of the interaction structure, so the emphasis is on the processes underlying the formation of a particular skill. According to this view, learning in information educational system is an active process aimed at extracting, constructing knowledge, and not just reproducing it. Training in this interpretation plays the role of supporting the student's constructive efforts to independent development of knowledge, skills and abilities [14, 15, 16, 17].

For students, a portfolio is an organizer of their learning activities, for a teacher it is a means of feedback and an evaluation tool. There are several types of portfolios. The most popular are the following: portfolio of achievements, portfolio-report, portfolio-selfassessment, portfolio-planning my work. Any of them has all the characteristics, but when planning, it is recommended to choose one, the leading one. The choice of portfolio type depends on the purpose of its creation. In this study, a portfolio of achievements and a portfolio report were used.

A distinctive feature of the use of pedagogical technology for creating a portfolio is its personality-oriented nature of the stages of its implementation [18]. In our study, we identified and analyzed three main stages of applying the pedagogical technology of an electronic portfolio created in cooperation between a teacher and students in order to use it as a means of improving their professional literacy.

At the first stage, students together with the teacher determine or specify the purpose of creating a portfolio. At the second stage, students collect material and add it to the electronic portfolio of the university's information and educational system. At the third stage, students' performance is verified and evaluated be the experts, with self-assessment and mutual evaluation.

An important characteristic of the pedagogical technology of the electronic portfolio is its reflexivity. Reflection is the main mechanism and method of self-certification and selfreporting. In addition to general academic skills to collect and analyze information, structure and present it, the portfolio allows students to develop intellectual skills of a higher ordermetacognitive skills, which are the main factors for the development of the level of professional literacy of the university students. In the process of working on an electronic portfolio, students should learn how to select and evaluate information, accurately determine the goals that they would like to achieve, plan their activities, give assessments and selfassessments, track their own mistakes and correct them [19, 20]. 
In this context, we consider the portfolio as one of the techniques most appropriate for the development of functional literacy. It is the student's portfolio that serves as a means of improving functional literacy and developing professional and meta-competencies by combining the possibility of developing critical thinking and a modern assessment method and makes it possible to diagnose the formation of the main goals. Upon reaching this level of professional literacy, a university student becomes capable of further building their own educational trajectory and ability to self-educate.

\section{Results}

As a result of our research, we analyzed potential threats to the students' development and training in virtual educational environment and identified the optimal stages of pedagogical management of educational content of the information educational environment of the University. We were able to present these stages in the form of a certain sequence of actions, the result of which was the predicted result. Thus, we received an educational technology of pedagogical management, which was tested by University students during the implementation of an electronic training course in a foreign language for non-linguistic specialties. The research also identified the best methods of interaction in the virtual educational process, interpersonal communication, as well as the most effective methods of achieving educational goals and monitoring the results of training and organization of pedagogical management, according to reports of the information educational system. It was noted that for effective implementation of pedagogical management procedures, ensuring the adoption of management decisions, the information educational environment should receive prompt, reliable and complete information about the state of the main parameters of the educational process. Such information can be obtained as a result of pedagogical monitoring as a purposeful, specially organized, continuous monitoring of changes in the basic properties of the pedagogical system. The purpose of implementing monitoring procedures is to promptly make adequate management decisions to correct the course of the educational process based on the analysis of the collected information and the pedagogical forecast.

The components of the electronic portfolio have a variable composition depending on the educational goals set by the university and the methods of their quantitative assessment. In our study, the electronic portfolio consists of: an individual curriculum; a training course divided into a course on the general education program and subjects that the student studies in more depth; a report on the student's qualification skills; a description of the production practice; projects and their results. Along with the listed sections, the electronic portfolio may contain individual personal data of the student (interests and hobbies). On the website of the university brief cases of students are provided by faculty. The portfolio page of a particular student contains the main presentation page, which reflects data about the student: last name, first name, patronymic, email address, faculty, group. The page may also contain any additional information that the student determines independently. General requirements apply to the portfolio structure, and the appearance and design of the portfolio may be made in accordance with the preferences of the account owner. The program provides an assortment of different fonts, backgrounds and styles. On the main page of portfolio, the user adds his photo, although this requirement is not mandatory. In addition to the presentation page, the student's portfolio has the main part, represented by the following sections:

1. Presentation letter. It describes the most important aspects of the educational process at the university, as well as a brief description of the structure of the electronic portfolio. You can also describe the tasks that are pursued by creating a portfolio.

2. The concept of education. This section describes the conceptual component of education in the student's opinion, the reasons for choosing this profession, plans for the future, the area in which students are developing at the moment and in which they would like 
to study.

3. Summary. This section contains a personal biography, lists the main processes-training at school, university, events in which the student participated; date of admission to the university; events in which he participated.

4. Individual characteristics. In this section, the student analyzes himself as a person, demonstrates his moral upbringing. For example, a student can describe people with whom it is pleasant to interact in the learning process.

5. Reflexive section. The section contains an analysis of directly educational and research activities, skills and achievements obtained in the process of creating a portfolio.

6. Certification of authorship. It is mandatory to confirm the accuracy of the data. Students are responsible for the information presented in the portfolio.

The electronic portfolio is filled with a collection of academic works and reflexive training materials. The university portal, designed for working with electronic portfolios, contains general information about the electronic portfolio method, tools for developing and developing a portfolio, development instructions and methodological materials that describe in detail the stages of development, as well as a gallery of student portfolios.

A qualitative and quantitative assessment of professional literacy was carried out on the basis of the developed questionnaires, as well as the features of the relationship between the electronic portfolio and the professional competence of students, the dynamics of their synchronous development were revealed. To systematize the results of using the electronic portfolio as a means of improving the professional literacy of university students and assessing the level of formation of their competencies, a simulation of the pedagogical process using the electronic portfolio was carried out.

The results show that the educational process in a virtual environment includes interrelated components, namely, the implementation of effective pedagogical management by the teacher and the actual development of educational Internet technologies by students. It is established that properly organized pedagogical management contributes to the maximum implementation of the unique features of the virtual educational environment. Also, 93\% of the participants in our study emphasized the broadest didactic tools and prerequisites for the intensification of the educational process in a virtual educational environment, new opportunities for developing students' intelligence, forming their moral priorities, and independently searching for information and producing it. In the course of the research, experimental virtual training courses for students of non-linguistic specialties in a foreign language were created.

To achieve the goal of our research, we analyzed the approaches to the concept of "portfolio" in modern pedagogical research; formed the main model of the portfolio, combining three aspects: the level of development of competencies, assessment by employers, personal and social characteristics; provided justification and defined the methodology for using the portfolio of a competitive university graduate.

The portfolio model we offer consists of three main components (see Fig. 1):

1. final data on the level of competence development;

2. the level of business, personal, social and other activity of the student, which is formed during the entire learning process;

3. assessment of the student by potential employers, which is formed in the course of practical training. 




Fig. 1. E-Portfolio Model

Thus, the purpose of developing a portfolio of a university graduate is not only to present the achievements of the student, his practical experience, level of education, but also to identify the potential of the future young specialist, determine the path of development, deepen the level of competencies, identify the dynamics of the development of his potential capabilities. The electronic portfolio also shows the degree of comprehensive development of the student. In turn, for the employer, this is an opportunity to assess the level of the candidate, the dynamics of his development and make the best decision about hiring. The results of our research are of a multi-structural nature, corresponding to a complex problem - a qualitative and multi-level assessment of competencies, measuring the individual progress of an educational institution graduate, self-presentation for employers, solved through an electronic portfolio.

\section{Discussion}

Our research has shown that the leading feature of pedagogical monitoring in the information educational environment is continuity. This feature of monitoring as a source of information for the implementation of pedagogical management procedures allows us to raise the question of giving a new property, namely, continuity to pedagogical management itself within the information educational environment. Continuous pedagogical management provides realtime implementation of information, analytical, planning, prognostic, diagnostic and correctional functions. At the same time, the efficiency of the entire process increases due to a significant reduction in the time lag between changes in the state of the pedagogical system and the formation of a controlling (corrective) influence. Accordingly, we propose to consider the technology of ensuring continuity as a key technology of pedagogical management within the information educational environment.

Based on our results, we can state that a necessary condition for the implementation of pedagogical management technology in a virtual educational environment is the use of continuous pedagogical monitoring. In turn, such monitoring is substantially based on new information technologies. Within the framework of the information educational space, the monitoring system is operatively linked to knowledge bases, which store, in particular, information about the current level of training, psychological characteristics of the student (including subject abilities) and the history of the learning process. Similar databases contain information about the tutor's work style, psychological characteristics, and activity history. To ensure the operation of such databases, it is necessary to create a formal model of the pedagogical process and its main subjects and maintain this model up-to-date. In particular, it is necessary to create a model of the current structure of knowledge, skills and abilities of 
the student, their competencies and individual psychological properties. It is also necessary to develop algorithms for building models, updating and correcting them, as well as algorithms for solving target tasks of pedagogical management on these models. Some of the mentioned tasks can be attributed to already solved ones. These include the problem of constructing theoretical models of systems of learning, development of algorithms for optimal selection systems of learning tasks and algorithms for the construction of individual educational trajectories of students. Thus, in the conditions of information educational environment the teacher retains its role of link in the process of quality management in education. Moreover, it acquires some new properties, the key of which is to ensure the continuity of internal information processes and, due to this, the information integrity of the entire space. This property, in turn, is the basis of the key technology for improving the effectiveness of pedagogical management - the technology for ensuring continuity. In the course of our research, we also noted that in the conditions of the information educational environment the most complete solution to meet the needs of subjects of the educational process can be achieved. It can be concluded that in the conditions of the information educational environment, there are prerequisites for improving the effectiveness of pedagogical management. The key technology for improving the effectiveness of pedagogical management in such conditions is the technology for ensuring continuity, based on continuous pedagogical monitoring. Continuous monitoring is based on formalized models of subjects and objects of the information environment. The monitoring system as part of the information educational environment interacts with the subject environment via these models.

In our study, we found that the model of a student's portfolio should consist of an integral assessment of his achievements: in the educational process (assessments in subjects, including the level of competence development), in professional activities (for example, passing training, industrial practices), in extracurricular activities (research work, sports events and others).

\section{Conclusions}

A unified information and educational environment can be understood as a computer-based software and telecommunications environment that provides information to the University management, teachers, students, their parents and the public using unified technological means. The technical basis of the virtual educational environment is a fleet of servers, personal computer workstations, and local area networks of the University's divisions, which are integrated into a high-speed corporate network. It is logical to distinguish the following elements in the structure of the virtual educational environment of the University: organization of the educational process, educational activities, university management, research work and extracurricular and educational work of students. The «educational activity» element is considered as a methodological basis for training students. In addition to mastering knowledge, it is also important to master techniques that can be used to obtain, process and use new information. At the same time, knowledge is acquired in relation to the skills that students master in the framework of innovative educational programs. That is why, in their best examples, educational portals of higher education institutions are focused not so much on the transfer of knowledge, which is constantly outdated, as on the acquisition of basic competencies that allow, as necessary, to acquire knowledge independently. Updated electronic educational and methodological complexes, which are placed on the educational server under the control of teachers, are designed to play an important role for independent training of students. When forming them, a system of hyperlinks is widely used, linking all the components of the complex, they also contain the main electronic full-text literary sources, and a kind of mini-library is provided for the student to organize independent work. 
These components of the electronic educational environment serve as the basis for pedagogical management of the educational process. A set of electronic assessment tools is widely used to control the acquired knowledge. The testing block allows you to determine the level of the acquired competencies in the mode of interactive individual dialogue between the student and electronic subsystems of the environment. For testing, the teacher specifies the name of the discipline, the type of control (current, intermediate, final), and provides a list of students admitted to the assessment. In order to form the main components of the «Educational Activity» element, in our research the University has successfully tested the Learning Management Systems (LMS) Moodle system, which compares with well-known commercial analogues in terms of the level of opportunities provided, but at the same time compares favourably with them in that it is distributed free of charge in open source code. Independent development of effective strategies for pedagogical management of the educational process by means of information technologies implies that the student must have a high level of information culture, the characteristics of which include: acceptance of the values of the information society at the personal level; awareness of the unity of humanitarian and technological cultures; possession of a sufficiently high level of functional literacy; knowledge of the system of information resources in their industry; active use of innovative computer technologies for searching and processing the necessary information; confident knowledge of information search skills; creative approach to developing strategies for their information activities. Thus, pedagogical management in the information educational environment is an integral and significant part of the educational activities of subjects of the educational process in the virtual environment. Pedagogical management expands the possibilities of developing the competence of a person who is freely oriented in the world information space, has the necessary knowledge and skills to search, store and use information, transform information, modify its form, representation, sign system, work with various media, translate verbal information into non-verbal and use modern information technologies, computer communications and systems for these purposes.

The use of the e-portfolio in the educational process requires a carefully developed methodology that would balance its weaknesses and strengths, ensuring a gradual transition from a purely traditional learning process to learning with a large share of the use of information technologies. The electronic portfolio is a multifunctional and flexible tool for improving the literacy of university students in a broad sense (presentation of material, control over assimilation, reflection and evaluation), however, this technology must be combined with traditional methods and with the advantages of a traditional approach to the learning process. Due to the fact that the considered approaches can be used in parallel and with greater efficiency than separately, it is necessary to develop a methodology for their combined use in the process of teaching students of higher educational institutions and to study the possibilities of using this technology at other levels of education.

Thus, the pedagogical technology of the electronic portfolio is an effective means of improving the functional literacy of university students and a modern effective form of assessment. The electronic portfolio complements traditional control and evaluation tools aimed at checking the reproductive level of information assimilation, factual and algorithmic knowledge and skills, including exams, and can in the future become a real alternative to traditional forms of assessment.

\section{References}

1. M.E. Ray, L. Dubrava, M. Jacks, Currents in Pharmacy Teaching and Learning 12(12), 1437-1446 (2020).

2. S.H. Ebil, S.M. Salleh, M. Shahrill, Education and Information Technologies 25(6), 5797-5814 (2020). 
3. N.Yu. Starobor, Intellectual resources for regional development 1, 258-261 (2018).

4. O.I. Ovcharenko, Matrix of scientific knowledge 5, 45-49 (2018).

5. S.Yu. Samokhvalova, T.V. Korneeva, Problems of modern pedagogical education 57, 184-191 (2017).

6. A.A. Polyaeva, Student science and the XXI century 14, 326-327 (2017).

7. O.I. Vaganova, A.V. Jigna, V.A. Trufanova, The advances of modern science and education 1(11), 18-19 (2016).

8. O. Fedotova, V. Latun, E. Platonova, I. Okuneva, E-portfolio as an Alternative Educational Technology and Means of Self-Presentation in the Labor Market: Scientometric Discourse, In: 9-th International Conference on Education and New Learning Technologies (EDULEARN17), Barcelona, 8886-8890 (2017) doi: 10.21125/edulearn.2017.0663.

9. T.K. Verenich, S.A. Zlobin, V.S. Srikan, Problems of Modern Education 3, 181-193 (2020).

10. O.V. Kuznetsova, L.P. Halyapina, Modern pedagogical education 3, 131-136 (2019).

11. D.A. Gusev, Science and School 5, 106-112 (2014).

12. K.A. Ummagine, Bulletin of the Moscow State Linguistic University 3(689), 109-120 (2014).

13. J. Gaida, Library Resources \& Technical Services 3(62), 149-150 (2018).

14. A.R. Aguilera, R. Griset, F. Santanach, G. Aguado, Digital Educational Material in the Editorial Process of Higher Education Online Courses: a Preliminary Report From an Open Educational Resources Perspective in Mexico and Spain, In: 4-th International Conference on Education and New Learning Technologies, (EDULEARN), Valencia, 1609-1615 (2012)

15. P. Hakkarainen, S. Poikela, Problem-based learning and collaborative information literacy in an educational digital video course, In: Practising Information Literacy: Bringing Theories of Learning, Practice and Information Literacy Together, Wagga, Center Information Studies, 67-94 (2010).

16. O.P. Osipova, Open and distance education 2(58), 76-82 (2015).

17. V.Yu. Mikhailov, Universum: Psychology and Education. 2(56), 12-14 (2019).

18. E.V. Meshcheryakova, Psychology and Pedagogy: Methods and Problems of Practical Application 36, 116-121 (2014).

19. D.F. Jabborova, Eurasian Union of Scientists 2(71), 20-22 (2020).

20. I.Yu. Kolpakova, A.A. Moskvitin, Advances in Modern Natural Science 10, 108-109 (2013). 